\title{
Study on the Mode of Bulk Commodity Circulation Operation on the Internet Platform in China
}

\author{
Xin LI \\ School of Management \\ Wuhan University of Science and Technology \\ Wuhan, China \\ E-mail: 353930944@qq.com
}

\author{
Kai-Ling PAN \\ School of Management \\ Wuhan University of Science and Technology \\ Wuhan, China \\ E-mail: pank10122@qq.com
}

\begin{abstract}
This paper first introduces the status quo of commodity circulation market, and then the model of commodity circulation is analyzed by SWOT-PEST matrix mode on the Internet Platform, it analyses the impact of the internal and external environment of commodity trade flows including the strength, weakness, opportunities, threats and the aspects of political, economic, social and technology, Finally, put forward the development strategies corresponding to the transformation and upgrading of China's commodity circulation.
\end{abstract}

Keywords-component; SWOT-PEST matrix model; commodity circulation; Internet Platform; development strategies

\section{INTRODUCTION}

Since the beginning of 21 st century, the form of commodity trading in our country has realized diversified circulation means, including commodity trading market, futures market, third party e-commerce platform, and traditional commodity trading system. The commodity circulation market has declined in recent years, to change the grim form has a long way to go. The continuous accumulation of economic problems in China's commodity market has brought great impact on the major enterprises, and some enterprises have shown negative growth in profits for several years, including Iron, petroleum, coal, cement, electrolytic aluminum, glass, shipbuilding and other commodities and other commodities industry production price index has been negative growth trend for 3 consecutive years, the extent of the decline in commodity markets increased gross profit. In 2016 the plan of supply side reforms, there is a huge rise of bulk commodity's price with severe fluctuate. The range of fluctuate is more than ever before, which makes the dim commodity market for many years there has been a stirring among the dry bones scene. However, there are many problems in the circulation of commodities in China. On the one hand, market defined by overcapacity, oversupply and utter sensory overload, at the same time, information resources lag, backward production capacity cannot effectively exit channels, overcapacity caused a great degree of pressure for commodity circulation,. On the other hand, China's commodity circulation efficiency is low, the cost is high, the informatization level needs to be promoted, and the whole country cannot build a large market and circulation environment [1].

\section{ANALYSIS MATRIX OF SWOT-PEST}

SWOT analysis method is used to determine the competitive advantage and disadvantage, opportunity and threat, which will be a scientific analyzing method and strategy of company's internal resources and external environment organically.

PEST is a macro environment analysis model for enterprises, which includes political, economic, social, scientific and technological. These are the external environment of an enterprise and are generally not controlled by the enterprise.

SWOT-PEST model comes from enterprise strategy analysis method. It is a strategic analysis method to identify its own advantages, disadvantages, opportunities and threats. The SWOT-PEST model is generally analyzed from two aspects: internal environment (advantages and disadvantages) and external environment (opportunities and threats). Each individual item can be analyzed concretely in terms of politics, economy, society and technology according to different objects of analysis. Then the contents listed in the matrix table1, including 4 strategies. The use of their own advantages to grasp opportunity advantage, overcome the disadvantage opportunity weaknesses in the grasp of opportunity. The use of their own advantages to deal with the threat of the advantage of threat and overcome disadvantages under threat.

TABLE I. MATRIX OF SWOT-PEST

\begin{tabular}{|c|c|c|c|c|c|}
\hline \multicolumn{2}{|c|}{ SWOT-PEST } & $\begin{array}{c}\text { politica } \\
1\end{array}$ & $\begin{array}{c}\text { economi } \\
\text { c }\end{array}$ & $\begin{array}{c}\text { socia } \\
1\end{array}$ & $\begin{array}{c}\text { technolog } \\
\text { y }\end{array}$ \\
\hline \multirow{2}{*}{ Internal } & strength & SP & SE & SS & ST \\
\cline { 2 - 6 } & weakness & WP & WE & WS & WT \\
\hline \multirow{2}{*}{$\begin{array}{c}\text { Externa } \\
1\end{array}$} & $\begin{array}{c}\text { opportunitie } \\
\text { s }\end{array}$ & OP & OE & OS & OT \\
\cline { 2 - 6 } & threats & TP & TE & TS & TT \\
\hline
\end{tabular}

\section{ANALYSIS MATRIX OF SWOT-PEST}

\section{A. Internal Strengths}

\section{1) Policy Strengths}

In order to accelerate the commodity circulation industry in the process of modernization, the government issued the 
plan of "On promoting online and offline interaction, accelerate the flow of Commerce, innovation, development, transformation and upgrading of views "Internet plus circulation" action plan and so on, to show business and modern logistics as the leading, sharing through the Internet, big data integration and information security and use, with innovative business service system, promote the commodity trading market to optimize the allocation of resources, through the Internet to promote energy system flat, promote energy production and consumption model revolution, improve circulation efficiency and resource utilization, save energy consumption and material cost. Popularize management system standards in the integration of informatization and industrialization, equipment, petrochemical, pharmaceutical, food and other key industries to foster a batch of national informatization and industrialization management system standard enterprise implementation, focusing on the implementation of the "Internet + traffic" and "Internet + circulation" action plan in bulk commodities key. To increase the importance and construction of the commodity circulation industry, the government pointed out the direction of action and planned the key points for the reform and upgrading of major industries [2].

\section{2) Economic Strengths}

In terms of platform statistics, to the end of 2015, domestic billions of dollars and above market commodity trading enterprises exceeded 5000, the transaction amount is close to 10 trillion, the commodity trading market in enterprises accounted for 1021, the real transaction amount exceeded 30 trillion yuan. Futures market turnover of 136 trillion and 470 billion yuan, to a certain scale to maintain for many years, ranking the forefront of world commodity trading. In 2016,the eight major commodities sectors, including steel, agricultural and sideline products, energy, chemicals, textiles, rubber and plastics, nonferrous metals and building materials, accounted for $68 \%$ of the bulk commodities, with an obvious increase in GDP. With the "Internet plus" action plan to open, the commodities sector by applying hitherto unknown attention, such as steel oil and other industries upstream and downstream businesses under the traditional line operation mode. Distribution lines for realizing the reasonable establishing trade, logistics, information, capital of the organic unity, to create high quality, high efficiency, low cost of modern logistics distribution system has a very important role.

TABLE II. NINE COMMODITY PRICES INDEX COMPARISON

\begin{tabular}{|c|c|c|c|c|c|}
\hline Industry & $\begin{array}{c}\text { December } 20 \\
16\end{array}$ & $\begin{array}{l}\text { month } \\
\text {-on- } \\
\text { month } \\
\text { basis1 }\end{array}$ & $\begin{array}{l}\text { Januar } \\
\text { y } 2017\end{array}$ & $\begin{array}{l}\text { year- } \\
\text { on- } \\
\text { year } \\
\text { basis }\end{array}$ & $\begin{array}{l}\text { month- } \\
\text { on- } \\
\text { month } \\
\text { basis2 }\end{array}$ \\
\hline energy & 1123.76 & $\begin{array}{c}+1.45 \\
\%\end{array}$ & $\begin{array}{c}1122.6 \\
4\end{array}$ & $-\overline{10 \%}$ & $+7.72 \%$ \\
\hline chemical & 888.45 & $\begin{array}{c}+5.56 \\
\%\end{array}$ & 899.31 & $\begin{array}{c}+1.22 \\
\%\end{array}$ & $19.07 \%$ \\
\hline rubber & 865.84 & $\begin{array}{c}+1.95 \\
\%\end{array}$ & 860.93 & $\begin{array}{c}- \\
0.57 \%\end{array}$ & $\begin{array}{c}+28.84 \\
\%\end{array}$ \\
\hline Spin & 852.35 & +4.61 & 972.23 & $\begin{array}{c}+1.41 \\
\%\end{array}$ & $\begin{array}{c}+18.65 \\
\%\end{array}$ \\
\hline $\begin{array}{c}\text { nonferrous } \\
\text { metal }\end{array}$ & 564.49 & $2.62 \%$ & 564.11 & $0.07 \%$ & $\begin{array}{c}+26.98 \\
\%\end{array}$ \\
\hline
\end{tabular}

\begin{tabular}{|c|c|c|c|c|c|}
\hline $\begin{array}{c}\text { Iron and } \\
\text { steel }\end{array}$ & 852.34 & $\begin{array}{c}+5.77 \\
\%\end{array}$ & 835.63 & $\begin{array}{c}- \\
1.96 \%\end{array}$ & $\begin{array}{c}+62.60 \\
\%\end{array}$ \\
\hline $\begin{array}{c}\text { Building } \\
\text { materials }\end{array}$ & 1123.57 & $\begin{array}{c}+1.16 \\
\%\end{array}$ & $\begin{array}{c}1115.7 \\
6\end{array}$ & $\begin{array}{c}- \\
0.69 \%\end{array}$ & $+9.30 \%$ \\
\hline $\begin{array}{c}\text { Agricultur } \\
\text { al and } \\
\text { sideline }\end{array}$ & 1229.94 & $\begin{array}{c}+0.19 \\
\%\end{array}$ & $\begin{array}{c}1209.1 \\
6\end{array}$ & $\begin{array}{c}- \\
1,69 \%\end{array}$ & $-3.69 \%$ \\
\hline
\end{tabular}

\section{3 ) Social Strengths}

With the gradually raise the living standards of social life in the diversified development, through the network platform to carry out the transaction, payment orders and other business model gradually from the new purchase mode has gradually become popular buying habits. Domestic electricity supplier market has trained a large number of customer groups, and this trend, enterprises have been looking for a favorable business model, and then upgrade to the electronic business platform, and effectively promote the enterprise transformation. It not only makes the modes of management and distribution of commerce a new look, but also straightly fastens the fluxion of resources and optimizes the collocating of resources, which also promotes the exaltation of consumptive notion and the change of consumptive environment[3].

\section{4) Technological Strengths}

At present, many developed countries have formed comparatively mature logistics management concepts, advanced logistics techniques and effective logistics operating systems. While the developing of international trade and market economy after opening reformation, the category of products in China is becoming abundance. Along with the country the logistics industry standard, and the foreign policy of transport enterprises constantly to enter the Chinese market to participate in the competition, our country logistics enterprise is gradually into a large-scale, regularization development.

\section{B. Internal Weaknesses}

\section{1) Policy Weaknesses}

China's commodity circulation market still exists in domestic and international market, the online market, the spot market futures market between fragmented regional urban and rural development is not in a balanced phenomenon, which restricts the healthy development of commodity trade circulation industry in China. And also Imperfect national credit management system, lack of efficient punishing mechanism towards the action of breaking faith. Relevant departments of this liquidity, high flexibility, cross-border trading system of market supervision system is not perfect. The internal management system is not perfect, lacking the effective drive and restraint mechanism. Over the years, there are some deficiencies and even defects in our political system which hinders the system of CPC Congress from functioning effectively [4].

\section{2) Economic Weaknesses}

In China, logistics cost accounts for $30 \%$ of the total cost of goods, transportation cost is three times higher comparing with Western countries. The logistics industry of our country develops backward, the cost of logistics is far higher than America, Europe and Japan. And the transportation cost of it 
occupies a fairly large proportion. By the end of 2016, the inventory rate of Industrial Enterprises above Designated Size in China was about $10 \%$, much higher than that of western developed countries. The proportion of the total logistics cost of GDP in the whole society was as high as $16 \%$, which was more than $5 \%$ times that of the developed countries. The turnover of industrial enterprises has only 2.5 times, far below the level of about 9-10 times in Japan and Germany, and also the great changes have taken place in the domestic market, featuring the shift from a seller's market to a buyer's market and the oversupply of many commodities.

In the 1-6 months of 2017, commodities in the energy sector all went up and down.

\section{3) Social Weaknesses}

Online shopping has been and popular recently, but experts believe that it cannot completely replace the traditional way of buying. According to statistics by the end of 2015, the national Internet penetration rate was $50.3 \%$, and with the popularity of different regions are different, Beijing, Shanghai, Guangdong penetration rate of over $70 \%$, while Yunnan, Guizhou, Gansu and other places are less than 40\%, due to geographical factors of the Internet penetration rate is extremely uneven. Although $60 \%$ of Internet users participate in online shopping and the number is increasing year by year, there are still a lot of people who do not understand the Internet technology, and the online shopping environment is very strange. People stuck to the limitations of the traditional model, the electronic business platform does not understand, it is difficult to effectively change the way to buy, the subsequent development of iron and steel in the electronic business platform is still difficult.

\section{4) Technological Weaknesses}

Security issues on the network platform to a large extent restricted the development of iron and steel electricity supplier. Some facilities and configuration of domestic network system lag behind, the corresponding platform protection hackers lower ability of network system crashes and data transmission recently frequent lag, accompanied by the leakage of personal information and payment security risks often let users doubt and anxiety. Steel electricity supplier ecological chain is not perfect, the existing platform only display product information, customer communication, and simple payment links and provide a single platform for propaganda, and financing, logistics tracking, customer service service processing is still in the preliminary exploration in the implementation.

\section{External opportunities}

\section{1) Policy Opportunities}

On the government to promote synergy "China manufacturing 2025" and "Internet plus", and "opinions of the State Council on the in-depth implementation of the" Internet plus circulation "action plan". Seizing the opportunity of "Internet plus" based on Internet technology application and innovation as the driving mode. To accelerate the development of "Internet plus circulation", it is helpful to promote the transformation and upgrade circulation of commodity. In December 29, 2016, the Ministry of Commerce, the central network information office, development and Reform Commission three departments jointly issued the "e-commerce development plan" in 13th Five-Year ".The national and local industry planning intensive introduction clearly put forward the new concept of commodity development. The related platform formally launched will also effectively enhance the right to speak of commodities and all kinds of information resources sharing and utilization efficiency, and promote the transformation of traditional industries, traditional commercial circulation enterprises and commodity trading market.

\section{2) Economic Opportunities}

Document "planning" established the "2020 e-commerce turnover of 40 trillion yuan, online retail sales of 10 trillion yuan, 50 million practitioners related to" three major indicators of development. From the planning objectives, it can be calculated, the remaining commodities and B2B ecommerce accounted for 30 trillion, absolute highlight of the field of e-commerce. Following the "Internet plus" program, the Internet industry A new force suddenly rises., and commodity prices continue to decline, B2B business platform for more than a decade seems to have found a new outlet, with the power of capital into various Internet Co B2B electricity supplier in the field of supply chain finance is becoming an important starting point for the B2B business platform, in October 2016 cross-border financial services platform formally launched in Shanghai Free Trade Zone, as payment for ecosystem revolutionary, the platform is built, the integration of Shanghai free trade zone is an important measure of the whole digital trading platform, FTA commodity cross-border electricity supplier to achieve new development, has important significance for promoting the internationalization of large transactions and financial services[5].

\section{3 ) Social Opportunities}

The 21 st century is a century of entrepreneurship, which has already become the dynamic of economic development. The new academic function of developing and industrializing high tech, improving the national competitiveness, productivity and entrepreneurship has been the important symbol of modern leading universities. The forthcoming new entrepreneurial epoch, in which entrepreneurship could stimulate employment, speed us to cultivate more entrepreneurial talents, who have entrepreneurial consciousness, quality and knowledge. "Internet plus" and the traditional industrial chain will enhance the depth of integration, the future of small and medium-sized enterprises Chinese competitive advantage, to promote industrial innovation speed towards the road. This creates opportunities for subsequent platform development.

\section{4) Technological Opportunities}

2017 (seventh) China Internet industry annual conference published in 2016 China Internet industry review and 2017 trends, it point that we should develop next-generation information infrastructure and modern IT industry, better ensure information security, and promote the application of information network technologies. Seizing the Opportunity to Accelerate Infrastructure Construction of China's Space Information, Improving and upgrading the traditional industry with advanced computer technology, network technology, 
communication technology and information technology is an effective way for our country to catch up with and surpass the powerful country of the world.

\section{External Threats}

\section{1) Policy Threats}

The government vigorously promote the "Internet plus" and the policy trend of transformation of traditional commodities industry, a large number of commodity Internet platform on the line, but the lack of standardized laws and regulations of the market supervision is not clear the main problems worthy of thinking, and the future of the commodity market threat. The commodity circulation market lacks a unified regulatory body, and there is no third party that can effectively supervise the market behavior, it caused high market turnover, low delivery, and fraud and other issues emerge in an endless stream.

\section{2) Economic Threats}

Firstly, steel prices decline, mainly in the early price increases too, the technical aspects of the callback needs. In fact, the development of China's steel industry is still facing serious challenges, foreign trade from the "double reverse", the excess capacity, but also has characteristics of "structural surplus". The Petroleum Exporting Countries (OPEC) and other oil producing countries expect to implement or partially implement the reduction agreement, the tightening of crude oil supply is expected to rise, it will help to consume high inventories, and make market confidence rise. Non-ferrous metals mostly financial attributes, with the black department price changes obvious features, including copper and aluminum, lead and zinc is strong and tin nickel weak. It should be pointed out that the agreement on the reduction of nonferrous metals enterprises has been implemented, which will be an important factor in the long-term support of the price trend. And then, the crude oil prices are strong, conduction to the chemical market, methanol, acetone, phenol and other prices to rise mainly. Natural rubber prices in 2016 rose $70 \%$. Plastic prices are benefiting from a rebound in upstream oil prices. The national real estate market differentiation is still evident. The paper industry ushered in a long absence spring. Product prices increase, corporate earnings growth, many listed companies .Cotton prices bottomed out, but the pressure of domestic textile enterprises is still upside down, heavy cost. With the development of agricultural science and technology, the global agricultural products bumper harvest for many years, the stock is high, for more than less, the price will tend downward, finally if we do not reduce the planting area, the price rebound or more difficult.

TABLE III. PRICE CHANGES IN EIGHT MAJOR COMMODITIES SECTORS

\begin{tabular}{|c|c|c|c|}
\hline Industry & Index & $\begin{array}{c}\text { Highest } \\
\text { point }\end{array}$ & $\begin{array}{c}\text { Year-on-year } \\
\text { change }\end{array}$ \\
\hline energy & 682 & 1042 & $-34.61 \%$ \\
\hline chemical & 815 & 1016 & $-19.78 \%$ \\
\hline
\end{tabular}

\begin{tabular}{|c|c|c|c|}
\hline rubber & 653 & 1129 & $-42.16 \%$ \\
\hline Spin & 857 & 1035 & $-17.20 \%$ \\
\hline $\begin{array}{c}\text { nonferrous } \\
\text { metal }\end{array}$ & 920 & 1074 & $-14.34 \%$ \\
\hline Iron and steel & 834 & 1005 & $-17.01 \%$ \\
\hline $\begin{array}{c}\text { Building } \\
\text { materials }\end{array}$ & 870 & 1053 & $-17.38 \%$ \\
\hline $\begin{array}{c}\text { Agricultural } \\
\text { and sideline }\end{array}$ & 905 & 1044 & $-13.31 \%$ \\
\hline
\end{tabular}

\section{3) Social Threats}

China's commodity Internet platform has been through many years of growth, has occupied a certain market size, but still in a growth stage. All kinds of commodities, including steel, cement, agricultural products and so on, are only beginning to emerge in the public eye in recent years. To ensure the stability of commodity circulation, the need for timely information processing, modern logistics technology, safety certification authority and the means of payment, circulation of capital flow window support, and these platform construction requires a lot of talent to maintain. Many enterprises Internet platform does not form a special team services, the actual flow of goods on the map hinder many, inefficient, cost time consuming, social recognition is not good. And with the progress of the society, rapid modernization needs of high-quality talent gap is increasing, especially at the end of the twentieth Century, the large university enrollment increase, it also demands for highquality personnel is more and more high.

\section{4) Technology Threats}

Compared with the developed countries, automation and informatization of the logistics management process is not enough, which greatly influenced the international competitiveness of enterprises and the capability of sustainable development. China's commodity circulation has not yet formed a logistics platform and logistics system. The handling system is not paid sufficient attention in most of the real logistic center. And most of the handling systems are arranged at the base of experience, lack of scientific planning and design. How to reduce logistic cost, improve service standard and make sure the products quality and safely is the problem should be solved.

\section{DEVELOPMENT STRATEGY OF COMMODITY INTERNET PLATFORM}

\section{A. Enterprise Informatization and Electronic Construction of Finance}

With the development of global finance, electronic trading has become the major form of financial trading. Meanwhile the need for high performance and highly reliable system is more and more acute. The accelerated process of electronic, international financial market integration and liberalization of steady progress, countries or regions to intensify the increasing financial supervision. At present, most of China's enterprises are in the stage of transformation, and the modern 
enterprise system has not yet been generally established, and the progress of enterprise informatization is not satisfactory. In 15000 large and medium-sized state-owned enterprises, only about $10 \%$ of them have realized enterprise informatization or have better information means. The use of Internet plus "to deep in commodity enterprise to need to vigorously strengthen the enterprise informatization. Payment and settlement of the Internet platform requires an electronic financial system, including cross-border, cross regional financial services electronic payment system, online settlement and payment needs to intensify efforts to build and improve quality.

\section{B. Development and Training of Human Resources}

In the light of the present conspicuous problems of deficient professional talents in physical distribution and low level in administration of our country, we should adopt various forms to accelerate the development and training of human resources in this field. So, the modern enterprise to in the fierce market competition invincible, must pay attention to human resource development and management, must pay attention to the cultivation of talents. Commodities Company should take timely differentiation strategy, cultivating their own core competencies, make full use of and play to their strengths, strengthen $\mathrm{R} \& \mathrm{D}$, marketing and human resources training, to enable enterprises to continuously strengthen and expand [6].

\section{Promote the Modernization of Commodity Logistics System}

In order to conform to the enterprise development trend, whose center is modernization and informationization, many domestic commodity companies have adopted modern logistics management method. The traditional manual operation was replaced by the automation of distribution system. It helps achieve zero inventory, reduce logistics costs and enhance competitiveness for enterprises and simplifies procedures to facilitate the user to improve the quality of service. Modern logistics has become an effective way to improve efficiency and re-duce cost for materials circulation nowadays. And to accelerate economy circulations become necessary method to enhance competitive edge and fundamental approach to gain more margins of numerous manufacturers, wholesalers and retailers. It hold that the issues such as the repeated construction, the homogeneous competition and the overcapacity are threatening the sustainable development of the Chinese ports. Therefore, the cost of logistics and resource consumption become insurmountable gap. The complete strategy design and policy system play a key role. We should take the modern circulation as the leading force of the circulation of commodities, reduce the cost and increase the input and output rate.

\section{ACKNOWLEDGMENT}

This research was financially supported by the school of Management of Wuhan University of Science and Technology and Graduate Student Education Research Project of Wuhan University of Science and Technology.

\section{REFERENCES}

[1] W L.Cheng,The Building of New Rural Areas and Modern Rural Commodity Circulation System."J. Commercial Research, 2007..

[2] X.D.Sun,X.H.Yang,and A.I.Guo Sheng Competitive Strategies for Appliance Enterprises in China under E-commerce."J. Industrial Engineering Journal, 2002, pp.1-5.

[3] L V. Huai-Tao,Will the Commodity Circulation Process Create Demand?_A New Research Perspective on the Value of Circulation.’J. Journal of Business Economics, 2015.

[4] C.Ma,Y.Wang The strategic choice of non-equity modes by Chinese enterprises under the current global financial crisis,"J. International academy of business and economics, 2012

[5] M.Momeni,M.Sarmadi,A Genetic Algorithm Based on Relaxation Induced Neighborhood Search in a Local Branching Framework for Capacitated Multicommodity Network Design,'J. Networks \& Spatial Economics, 2016,pp:447-468.

[6] T.C.Wang,Y.L.Lin,Accurately predicting the success of B2B ecommerce in small and medium enterprises,"J. Expert Systems with Applications, 2009, pp.2750-2758 